\title{
$O$ infinitivo flexionado do português paulista dos séculos XVIII, XIX e XX: um estudo sintático-diacrônico ${ }^{1}$
}

\author{
Sarah Cristina Silva Leite Vargas \\ Universidade Federal de São Paulo (UNIFESP), Guarulhos, São Paulo, Brasil \\ sarah_csleite@hotmail.com \\ https://orcid.org/0000-0003-3635-9595
}

\section{DOI: http://dx.doi.org/10.21165/el.v47i1.2017}

\begin{abstract}
Resumo
Este estudo apresenta uma análise sobre o infinitivo flexionado dos séculos XVIII, XIX e XX sob uma perspectiva diacrônica. Por meio do estudo dos infinitivos flexionados (MAURER JR., 1968; RAPOSO, 1987; PIRES, 2006; SALLES, 2006; MARINS, 2009; MODESTO, 2011) e de estudos de sintaxe diacrônica, foram analisadas ocorrências desse fenômeno em textos do português paulista dos séculos mencionados, tomando como base para a análise o parâmetro do sujeito nulo (DUARTE, 1995). O enfraquecimento da flexão dos verbos no português brasileiro é crescente (GALVES, 1993), contudo o infinitivo flexionado contraria essa perda de flexão, sendo utilizado mesmo na escrita em contextos em que não está prevista sua ocorrência (CANEVER, 2012). Nos textos paulistas, observamos os contextos de presença dos infinitivos e o seu crescimento e, no último século, uma presença mais restrita. Por meio do Parâmetro do Sujeito Nulo, foram analisados trechos de cartas, a fim de entendermos o processo de enfraquecimento da flexão no português brasileiro e o crescimento da realização do sujeito.
\end{abstract}

Palavras-chave: infinitivo flexionado; sintaxe diacrônica; sujeito nulo.

The inflected infinitive of the São Paulo Portuguese of the eighteenth, nineteenth and twentieth centuries: a syntactic-diachronic study

\begin{abstract}
This study presents an analysis of the inflected infinitive of the 18th, 19th and 20th centuries from a diachronic perspective. Throughout the study of the inflected infinitives (MAURER JR., 1968; RAPOSO, 1987; PIRES, 2006; SALLES, 2006; MARINS, 2009; MODESTO, 2011) and studies of diachronic syntax, we have analyzed occurrences of the phenomena highlighted in texts of the São Paulo Portuguese of the centuries mentioned, taking as a basis for the analysis the parameter of the null subject (DUARTE, 1995). The weakening of the verbal inflection in Brazilian Portuguese is increasing (GALVES, 1993); however, the inflected contravers this loss of inflection, being used even in writing in contexts in which it is not predicted to occur (CANEVER, 2012). In the texts of São Paulo, however, we observe the contexts of the presence of infinitives and growth and, in the last century, a more restricted presence. By means of the Null Subject Parameter, we analyzed sections of letters in order to understand the weakening process of the inflection in Brazilian Portuguese and the growth of the realization of the subject.
\end{abstract}

Keywords: inflected infinitive; diachronic syntax; null subject.

\footnotetext{
${ }^{1}$ Agradeço à CAPES e à Universidade Federal de São Paulo pela verba concedida para participação no $65^{\circ}$ Seminário do GEL.
} 


\section{Introdução}

Este trabalho tem por objetivo a descrição dos infinitivos flexionados do português paulista dos séculos XVIII, XIX e XX por meio do parâmetro do sujeito nulo. Esse estudo em andamento irá abordar dados de diacronia e, consequentemente, poderá englobar um estudo/descrição da variação e mudança gramatical. O parâmetro do sujeito nulo nos permitirá compreender a mudança paramétrica dentro do português brasileiro. Pesquisas sobre o sujeito nulo no português brasileiro (doravante PB) e a flexão infinitiva nos ajudam a entender o porquê, como já descrito por Galves (1993), de a flexão no infinitivo ter se mantido e expandido no português culto falado ou escrito (Cf. CANEVER, 2012), e ter se tornado fraca em contextos finitos.

A proposta deste trabalho aborda a Linguística Histórica sob um viés gerativo. A Linguística Gerativa está aqui representada por meio do Parâmetro do sujeito nulo - para uma descrição diacrônica (KROCH, 1989; PAIXÃO DE SOUSA, 2004; CAVALCANTE, 2006) dos infinitivos flexionados presentes nos corpora do Projeto de História do Português Paulista (PHPP) dos séculos XVIII, XIX e XX, como é possível observar nos trechos das cartas da Biblioteca Nacional do Rio de Janeiro:

(1) Meu charo Amigo, no dia 25 tivemos a incomparavel honra de vermos no nosso solo onosso Idolatrado Principe (BNRJ 01)

(2) hum grande numer de honrados Cidadaõs la se haõde achar na certeza $\mid$ de serem preteridas suas vontades para maioria contraria dos sapatoens. (BNRJ 02)

(3) he de crer, que sejaõ pobres, eindigentes sem meios, sem forças para promoverem as utilidades, e bens mais da agricultura. (BNRJ 04)

O infinitivo flexionado se apresenta apenas na língua portuguesa e em outros poucos dialetos e possui características específicas (Cf. LUZ, 1994; RAPOSO, 1987) por ser um infinitivo que recebeu desinências verbais após ter recebido um sentido pessoal (Cf. MAURER JR., 1968). Os estudos de Leite de Vasconcelos (1900) consideram o infinitivo pessoal, ao apresentar as sentenças "Ter saúde é bom" e "Ter eu saúde é bom", ou seja, o emprego deixa de ser impessoal e se torna pessoal e são acrescentadas desinências número pessoais ao verbo (Cf. CARVALHO; MINUSSI, 2016). O infinitivo teria adquirido pessoalidade por admitir sujeitos nominativos, uma vez que o sujeito nominativo conferiu às formas infinitivas um sentido pessoal. Maurer Jr. (1968) explica que os falantes teriam transferido as flexões do futuro do subjuntivo nos verbos regulares, derivando as formas flexionadas do infinitivo. "O infinitivo com sujeito no caso nominativo precedeu certamente o infinitivo flexionado e foi, sem dúvida, o fator decisivo de seu aparecimento.” (MAURER JR., 1968, p. 70). Maurer Jr. (1968) propõe algumas regras para o uso do infinitivo flexionado, contudo aponta que a principal delas é: o infinitivo é flexionado quando há a realização do sujeito na sentença.

Há duas hipóteses principais para o surgimento do infinitivo flexionado em português, que são apontadas por Maurer Jr. (1968). Estudos como os de Wernecke (1885) e Rodrigues (1914) apontam que a flexão infinitiva é derivada do futuro do subjuntivo imperfeito latino, enquanto estudos como de Maurer Jr. (1968) mostram o infinitivo flexionado como uma variante finita do infinitivo românico. A hipótese que apresenta a flexão infinitiva como uma derivação do imperfeito do subjuntivo latino argumenta que essa forma verbal existia no latim vulgar na região da Galícia e Portugal durante a Idade Média e teria passado a ser empregado com funções do infinitivo românico. O que reforça essa hipótese são os seguintes argumentos: (i) a supressão da 
conjunção em sentenças finitas subordinadas com o verbo no imperfeito do subjuntivo, que teriam sido equiparadas com sentenças subordinadas infinitivas, bem como (ii) o rearranjo sintático no qual o mais que perfeito do subjuntivo substituiu o imperfeito do subjuntivo (Cf. MARTINS, 2001).

Para Raposo (1987), o infinitivo flexionado está relacionado à AGR, independente da realização morfológica dos morfemas de concordância. A análise de Raposo propõe que a flexão do infinitivo no português europeu (PE) é dependente de dois parâmetros distintos, um morfológico (Infl parameter) e um sintático (Parâmetro do Sujeito Nulo).

O infinitivo flexionado no PE surge da possibilidade de haver um Infl infinitivo especificado com traços de Agr e de Tempo [[-Tempo, +Agr]. Em muitas línguas, a escolha de [Tempo] é livre, devido à escolha positiva de Agr. Contudo, na maioria das línguas essa escolha não é livre. Essas opções potenciais são chamadas de Infl Parameter e, como dito acima, o PE marca positivamente esse parâmetro.

Entende-se, dessa forma, que a flexão infinitiva está associada à presença de marcas de flexão e à presença de AGR capaz de atribuir Caso nominativo ao sujeito. Questiona-se a relação entre a riqueza de AGR e a manifestação do morfema de concordância. No infinitivo flexionado, há morfema $\emptyset$ de flexão na primeira e na terceira pessoas do singular no PE e para o PB na primeira, na segunda e na terceira pessoas do singular. De acordo com os dados do presente estudo, é possível que haja um sincretismo de formas entre flexão infinitiva e não-flexão infinitiva (a flexão zero). Há casos em que não há manifestação de morfema, mas há uma flexão. $\mathrm{O}$ infinitivo flexionado possui, também, características relacionadas à questão do controle, da referência e do tipo de complementação infinitiva.

O presente trabalho, como já dissemos, irá descrever o infinitivo flexionado utilizando-se de um corpus formado por cartas dos séculos XVIII, XIX e XX. Assim sendo, trabalhos como o de Cavalcante (2006), que apresenta um estudo diacrônico do infinitivo português, são de grande importância para este artigo, uma vez que nos ajudam a discutir a sintaxe relacionada ao infinitivo. Fazer um estudo diacrônico sobre os contextos de infinitivo contribui para entender aspectos do sistema de concordância do português, mais especificamente, como se mantém o sistema de concordância verbal em contextos de infinitivo flexionado, mas não totalmente em outros.

Os critérios usados para seleção do corpus foram obtidos por meio do conceito de tradições discursivas, buscando textos que apresentassem os mesmos traços, por exemplo: (i) tipos de verbos que admitem flexão, (ii) tipos de verbos que acompanham o infinitivo flexionado, (iii) traço [ \pm humano] e, em destaque, (iv) a narratividade dos textos (Cf. KEWITZ, 2007). Por meio do estudo do Parâmetro do Sujeito Nulo, foram analisados trechos de cartas, a fim de entendermos o processo de enfraquecimento da flexão no português brasileiro.

\section{A flexão infinitiva}

Segundo Raposo (1987), morfologicamente, o infinitivo flexionado no PE é formado pela adição do morfema -r e um marcador de concordância, cuja morfologia é a mesma não importando a qual classe de conjugação o verbo em particular pertença (RAPOSO, 1987). Sintaticamente, as sentenças com infinitivo flexionado (IF) são como as sentenças finitas devido à presença de sujeito lexical, mas, ao contrário delas, apenas 
ocorrem encaixadas, ou seja, não são independentes, e nelas não se admite o complementizador que. Raposo (1987) apresenta as situações no PE em que ocorre infinitivo flexionado, licenciando um sujeito lexical. São elas:

i) Complementos infinitivos [+Agr] ocorrem como orações subordinadas subjetivas em posição extraposta: o infinitivo com flexão e concordância [+Agr] opõe-se a infinitivo sem flexão e concordância[-Agr] (Vai ser difícil eles aprovarem a proposta);

ii) Infinitivos $[+\mathrm{Agr}]$ podem ocorrer em orações subcategorizadas por predicados matrizes epistêmicos (pensar), declarativos (afirmar), factivos (lamentar); não podem, porém, ocorrer em complementos subcategorizados por predicados volitivos (desejar) (Eu acredito os deputados terem trabalhado pouco);

iii) $\mathrm{O}$ verbo infinitivo que incorpora a flexão pessoal deve preceder o sujeito lexical com predicados matrizes epistêmicos e declarativos; essa restrição não se aplica, no entanto, aos verbos factivos (Eu detesto as pessoas usarem os outros);

iv) Complementos infinitivos [+Agr] ocorrem em orações adjuntas introduzidas por preposição (Eu entrei em casa sem os meninos verem);

v) Complementos infinitivos [+Agr] não podem ocorrer como orações encaixadas interrogativas, como orações encaixadas relativas, ou em construções com operador nulo em $\mathrm{C}^{\mathrm{o}}$; nesse contexto só cabem orações infinitivas com infinitivo [-Agr].

Raposo (1987) aponta três questões que nos parecem importantes sobre o IF: (i) quais são os parâmetros da GU que tornam o IF possível no PE?; (ii) quais são suas propriedades básicas?; (iii) qual é o princípio da GU que determina essas propriedades? $\mathrm{O}$ autor adota a Teoria X-barra para a sua análise do IF e a Teoria do Caso para explicar as propriedades das sentenças com IF. Para o autor, o IF decorre da interação de um parâmetro morfológico - Parâmetro Infl - e um parâmetro sintático - Parâmetro do Sujeito Nulo.

De acordo com o Parâmetro Infl, os verbos podem ter valores [ \pm Tempo], [ \pm AGR]. $\mathrm{O}$ autor discute que em PE o parâmetro é positivo, logo existe a escolha livre de [ \pm Tempo] em um Infl, assim, o IF seria [-T][+Agr]. Por sua vez, para solucionar a atribuição de Caso, o estudioso vale-se da Teoria de Caso, afirmando que "na ausência de [+T], Infl (ou Agr em Infl) é capaz de atribuir Caso nominativo para o sujeito lexical se ele for especificado para Caso" (RAPOSO, 1987, p. 92), pois Agr carrega propriedades nominais como número, pessoa e, em algumas línguas, gênero (traços-phi). Porém, Agr pode ou não ser especificado para Caso de acordo com o Parâmetro do Sujeito Nulo. Em línguas de sujeito nulo, Agr pode atribuir Caso. Dadas estas considerações, o autor apresenta o IF no PE da seguinte forma: NP [-Tempo] [+Agr].

A consequência fundamental dos postulados da teoria de Princípios e Parâmetros para os estudos diacrônicos, segundo Galves (2001), é que o conjunto de fenômenos atestando uma mudança deve ser explicado por uma só causa profunda. Galves (2001) considera o elemento de concordância da flexão do PB "fraco". A concordância é fraca quando não contém pessoa, ou contém pessoa como um traço puramente sintático. Isso corresponde a uma concordância fraca morfológica e semanticamente.

Os dois componentes da flexão - Tempo (T) e Concordância (Agr) - são dois núcleos independentes na estrutura profunda, que se afixam no decorrer da derivação e Agr domina T. No final da derivação, a flexão tem como núcleo a concordância (Agr). 
Galves (1991) propõe que um morfema de concordância fraco não é gerado debaixo de um núcleo independente, mas como um afixo de $\mathrm{T}$.

No PB, um núcleo Agr, independente da realização morfológica, domina o sintagma temporal de sujeito suplementar, o que explica os diversos fenômenos de língua orientada para o tópico. O enfraquecimento da flexão tem como efeito uma reorganização da oração, em que o sujeito se encontra numa posição mais baixa do que numa língua de concordância forte.

Em seu trabalho sobre o infinitivo flexionado e a legitimação de AGR, Galves retoma Raposo (1987) e apresenta a proposta do pesquisador sobre as sentenças de IF em PE. V-AGR ocorre em uma posição para a qual algum Caso possa ser atribuído e, dessa forma, "na ausência de [+Tempo], Infl (ou AGR em Infl) é capaz de atribuir Caso nominativo a um sujeito lexical se ele mesmo for especificado para Caso." (RAPOSO, 1987, p. 92).

Verbos factivos e epistêmicos não legitimam o AGR encaixado. Para verbos epistêmicos e declarativos, a única posição disponível, segundo Raposo, para o verbo flexionado no complemento infinitivo é a de pré-sujeito, ocupada por verbos auxiliares.

Galves retoma que, para Raposo (1987), verbos factivos e preposições selecionam complementos [+N], seleção essa que é satisfeita por AGR em Infl e por sua projeção IP. Agr, assim, pode receber Caso de fora, já que esse é o núcleo do complemento do verbo principal ou da preposição. Em sentenças com sujeito extraposto, a oração em que o sujeito ocorre também é IP, seu AGR recebe o Caso por co-indexação com Infl da matriz.

$\mathrm{Na}$ análise de Galves (2001), há uma substituição do Parâmetro Infl de Raposo e há a asserção de que complementos infinitivos flexionados encaixados são sempre CPs. A autora apresenta os pressupostos da análise de Raposo (1987), mostrando que a atribuição de Caso para AGR por verbos factivos e epistêmicos depende de certos pressupostos, que para Galves são problemáticos.

Os verbos que admitem IF em seus complementos atribuem Caso, mas esse pressuposto é questionável. A autora ressalta que muitos verbos epistêmicos exigem um objeto PP em PE, como em (4):

(4) a. Não acredito *(n)esta história.

b. Eu penso *(n)esta pessoa.

O estudo ainda destaca que esses verbos não admitem miniorações adjetivas ou nominais, o que é possível observar em (5):

(5) a. *Acredito a Maria doente.

b. *Penso o João um imbecil.

Um verbo passivo não admite um complemento IF, mas o trabalho de Raposo (1988 apud GALVES, 2001) apresenta uma sentença contrária à postulação anterior:

(6) Foi lamentado pelo professor os meninos terem roubado o livro.

Galves observa que, nos complementos de verbos epistêmicos e declarativos, em Raposo (1987), AGR tem de ser alçado a Comp para receber seu Caso, mas somente os auxiliares passam por esse alçamento. 


\section{O Parâmetro do Sujeito Nulo e sua marcação no PB}

Com o desenvolvimento da Gramática Gerativa, Chomsky (1981) apresenta a Teoria de Princípios e Parâmetros, partindo da ideia de que a Gramática Universal (GU) é formada por princípios gerais que atuam nos diferentes módulos em que a gramática é dividida. Os princípios compreendem as questões comuns presentes em todas as línguas naturais; a variação entre as línguas pode ser explicada pela noção de parâmetro. Parâmetro é como um princípio flexível, desenvolvido no processo de aquisição de língua e terá sua valoração definida ao final desse processo. A fixação de um parâmetro se dá por meio do input.

A partir da ideia de que parâmetros são conjuntos de propriedades do sistema gramatical, que têm seu valor fixado por meio da informação positiva do input, explicaremos o Parâmetro do Sujeito Nulo.

Algumas línguas, como o PE e o italiano, licenciam o apagamento do sujeito e marcam o PSN positivamente, ou seja, são [+pro drop]; outras línguas, como o inglês, marcam esse parâmetro negativamente [-pro drop], ou seja, o sujeito é uma categoria que necessita de material fonético.

Há alguns aspectos que outorgam a não realização fonética do sujeito. Acreditavase que esse parâmetro estava relacionado à morfologia do paradigma verbal. Dessa maneira, línguas como o italiano, que trazem seis oposições no paradigma flexional do verbo, licenciariam o sujeito nulo, identificado por meio da desinência. Entretanto, estudos como os de Huang (1984) mostraram que o chinês, por exemplo, exibe um paradigma verbal uniforme, mas permite o apagamento e a identificação do sujeito.

Em Roberts (1993), há uma nova proposta para o sujeito nulo: um paradigma morfologicamente igual deixa de ser condição para o licenciamento do sujeito nulo. Se um paradigma apresentar um número limitado de oposições, ele poderá licenciar um sujeito nulo, por isso pode haver sincretismo entre formas que indiquem mais de uma pessoa gramatical.

O PB se apresenta de maneira diferente de línguas de sujeito nulo. Duarte (1995) aborda que, no $\mathrm{PB}$, o preenchimento da posição de sujeito na sentença ocorre de forma ampla. O PB também não apresenta mais a inversão "livre", o que pode ser observado pela preferência da ordem SVO. Barbosa, Kato e Duarte (2005) trazem em seu estudo que o PB rejeita, na maioria das vezes, o verbo em primeira posição, mesmo com pronome nulo referencial ou um expletivo nulo. Há também uma preferência por pronomes resumptivos em orações encaixadas (Cf. MARINS, 2009).

A realização do sujeito nulo no PB não é obrigatória; é possível notar que há uma preferência pelo preenchimento da posição de sujeito, por sua realização fonética. Em línguas que marcam positivamente o PSN, o Princípio "Evite Pronome", que corrobora no apagamento do sujeito, é dominante.

Segundo Duarte (1995), o PB se mostra diferente das outras línguas românicas, pois o sujeito nulo não é obrigatório e há preferência pelo preenchimento dessa posição, mas isso não representa um uso marcado. Sentenças com sujeito nulo, entretanto, são amplamente aceitas e gramaticais no $\mathrm{PB}$, mostrando que o $\mathrm{PB}$ perdeu o princípio "Evite Pronome", marcando negativamente o PSN. 
$\mathrm{O}$ PB tem se afastado das demais línguas românicas no que se refere à marcação do Parâmetro do Sujeito Nulo. O PB, diferente do português europeu (PE), tem se comportado de uma forma que nos mostra uma mudança paramétrica de língua [+pro drop] para língua [-pro drop]. Estudos como os de Duarte (1995) apresentam a redução do quadro pronominal e a redução do paradigma flexional do verbo. Pesquisas recentes apontam que há parâmetro parcial, micro e macro parâmetro (SHEEHAN, 2010) e que o PB apresenta, então, um parâmetro parcial para Sujeito Nulo. Essa discussão é importante para o presente trabalho para observação dos sujeitos presentes no corpus.

\section{Os infinitivos flexionados do português paulista dos séculos XVIII, XIX e XX e o parâmetro do Sujeito Nulo}

Nesta seção, apresentamos os dados selecionados a partir do corpus do Projeto de História do Português Paulista (PHPP), (i) uma breve introdução sobre o que é o infinitivo flexionado, (ii) a apresentação dos dados, (iii) as divisões das cartas por século, (iii) as ocorrências de infinitivo flexionado em cada século, (iv) os tipos de sujeito (nulo e referencial) que acompanham o fenômeno destacado e (v) os tipos de sentenças infinitivas.

Por meio das ocorrências de flexão infinitiva selecionadas no corpus de cada século, foi feita a contagem de quantas ocorrências apresentam sujeito nulo e quantas apresentam sujeito não nulo. Segundo Duarte (1995), o PB apresenta uma larga preferência pelo preenchimento da posição de sujeito mesmo quando a flexão poderia garantir a interpretação de sujeito nulo.

\subsection{Os sujeitos no século XVIII}

Passamos, então, a um estudo mais aprofundado, analisando os sujeitos das sentenças em que há flexão infinitiva no corpus do presente trabalho. Apresentaremos, a seguir, tabelas e gráficos que nos ajudarão a entender os dados coletados sobre os sujeitos do corpus.

Tabela 1: Ocorrências de IF no século XVIII

\begin{tabular}{l|l|l|l}
\hline Variáveis & Sujeito realizado & Sujeito nulo & Total \\
\hline Quantidade & 16 & 39 & 55 \\
\hline Porcentagem & $29,1 \%$ & $70,9 \%$ & $100 \%$ \\
\hline
\end{tabular}

No século XVIII, o primeiro século destacado no presente estudo, há mais sujeitos nulos acompanhando as sentenças de infinitivo flexionado. Nos exemplos em (7) podemos observar, primeiro, algumas sentenças em que há a realização do sujeito:

(7) a. para elles ficarem mais Sua vontade [AI 15]

b. Sendo aCauza, deter admoestado ao dito Tenente puseSse cobro nosSeos filhos eescravos

por Serem estes perturbadores das Almas da dita aldeia [AI 19]

No exemplo em (8) selecionamos alguns trechos das cartas de Aldeamento de índios em que há sujeito nulo, que é o mais presente no século XVIII. 
(8) a. MediSse, agora medisse hua India, que o Capitam da aldeia tinhá ordem do Senhor Joseph para vegiar as Indias, que entraSsem dentro desta Casa alevar alguâ couza, compena de Serem a Soutadas [AI 19]

b. Isto hê oque querem para viverem como Gentio

c. ao brigacoins deque Sam em Carre-gados pelo Directorio, que he fazerem Roça demilho, fejaõ, e Arros, dar em agua e Lenha, huma CoSinheira, e hum Rapas para lheajudar a Missa

Há uma preferência pelo sujeito nulo acompanhando a flexão infinitiva no século XVIII; isso ocorre em mais de $70 \%$ das ocorrências do século XVIII. Ao final da seção, poderemos comparar os dados deste primeiro século com os dados dos demais séculos para confirmar ou não a prevalência do sujeito nulo.

A partir da seleção das sentenças de infinitivo flexionado, foi feito um levantamento dos tipos de orações que acompanham o fenômeno em destaque nessa pesquisa. No século XVIII, as sentenças se dividem da seguinte forma: (i) orações encaixadas com outro conectivo (conjunções, pronomes); (ii) orações encaixadas com preposição; (iii) orações matrizes; (iv) orações encaixadas completivas verbais; (v) orações encaixadas completivas nominais. Na tabela abaixo podemos observar como ocorre a distribuição de cada oração e quais são os tipos de orações em que há sujeito nulo e sujeito realizado.

Tabela 2: Tipos de oração com infinitivo flexionado no século XVIII

\begin{tabular}{|c|c|c|c|c|c|c|}
\hline \multirow{3}{*}{$\begin{array}{c}\text { Tipos de Oração } \\
\text { Orações encaixadas com outro conectivo }\end{array}$} & \multicolumn{2}{|c|}{ Sujeito Nulo } & \multicolumn{2}{|c|}{$\begin{array}{c}\text { Sujeito } \\
\text { Realizado }\end{array}$} & \multicolumn{2}{|c|}{ Total } \\
\hline & $\mathbf{N}^{\mathbf{o}}$ & $\%$ & & $\%$ & $\mathbf{N}^{\mathbf{o}}$ & $\%$ \\
\hline & 11 & $91,67 \%$ & 1 & $8,33 \%$ & 12 & $100 \%$ \\
\hline Orações encaixadas com preposição & 22 & $70,97 \%$ & 9 & $29,03 \%$ & 31 & $100 \%$ \\
\hline Orações matrizes & 0 & $0 \%$ & 1 & $100 \%$ & 1 & $100 \%$ \\
\hline Orações encaixadas completivas verbais & 4 & $80 \%$ & 1 & $20 \%$ & 5 & $100 \%$ \\
\hline Orações encaixadas completivas nominais & 3 & $50 \%$ & 3 & $50 \%$ & 6 & $100 \%$ \\
\hline
\end{tabular}

A tabela acima nos mostra que, das 55 ocorrências de infinitivo flexionado presentes no século XVIII, 31 foram encontradas em orações encaixadas com preposição. Do total de orações de infinitivo flexionado, foram encontradas 31 orações encaixadas com preposição, que contam $56,37 \%$ do total de orações; 12 orações encaixadas com outro conectivo, compondo $21,81 \%$ do total; 1 ocorrência de oração matriz, que corresponde a 1,82\%; 5 orações encaixadas completivas verbais, que são $9,1 \%$ das orações de infinitivo flexionado; 6 ocorrências de orações encaixadas completivas nominais, que correspondem a $10,9 \%$ do total de orações com flexão infinitiva.

Destarte, percebe-se que, no século XVIII, havia uma prevalência de sujeito nulo sobre o sujeito realizado. O corpus representativo do século XVIII mostra que o português paulista indicava uma preferência pelo não preenchimento do sujeito, como visto em Gravina (2008) sobre o português mineiro. Nesse século há, também, uma predileção pelas orações encaixadas com preposição para as ocorrências de infinitivo flexionado. 


\subsection{Os sujeitos no século XIX}

Apresentaremos agora os dados dos sujeitos das orações de infinitivo flexionado do século XIX e estabeleceremos uma comparação com o que foi mostrado sobre o século anterior, a fim de identificarmos qual é o tipo de sujeito predominante nesses dois primeiros séculos destacados nessa pesquisa.

Tabela 3: Ocorrências de IF no século XIX

\begin{tabular}{l|l|l|l}
\hline Variáveis & Sujeito realizado & Sujeito nulo & Total \\
\hline Quantidade & 21 & 28 & 49 \\
\hline Porcentagem & $42,86 \%$ & $57,14 \%$ & $100 \%$ \\
\hline
\end{tabular}

O século XIX parece acompanhar o previsto pelo século anterior: há uma predileção pelo sujeito nulo, mas a quantidade de ocorrências de sujeito não nulo não é bastante inferior. São 21 ocorrências de flexão infinitiva com sujeito realizado, $42,86 \%$ do total de ocorrências, e 28 ocorrências de sujeito nulo com infinitivo flexionado, que correspondem a 57,14\% das orações de infinitivo flexionado do século XIX. Em (9), há exemplos das ocorrências de infinitivo flexionado com o sujeito nulo nas Cartas Paulistas da Biblioteca Nacional do Rio de Janeiro e da Correspondência Passiva de Washington Luís:

(9) a. Meu charo Amigo, no dia 25 tivemos a incomparavel honra de vermos | no nosso solo onosso Idolatrado Principe [BNRJ 01]

b. Da ordens pre $=\mid$ cizas para a plantaçaõ de canas, e carpiçaõ das que estiverem no matto. [BNRJ 03]

c. As matriculas acham-se abertas e é bom approveitares a ocasião para occupares um dos primeiros lugares de ordem [CPWL 13]

Nessas cartas, também há uma forte presença da flexão infinitiva em $2^{a}$ pessoa do singular $(t u)$, o que não ocorre nos outros conjuntos de cartas. No trecho em $(9 \mathrm{c})$ há duas ocorrências de infinitivo flexionado na segunda pessoa do singular. Pelo fato de, no século XIX, a forma conservadora (tu) ainda prevalecer sobre a forma inovadora (você) há esse tipo de ocorrência.

Agora, nos exemplos em (10) poderemos observar as ocorrências de infinitivo flexionado em que há sujeito realizado:

(10) a. Estando Membros d' | alguã Villas, ainda assim tenho feito, que se naõ tenha installado | a Junta, a espera de Sorocaba, que ainda naõ o quiz mandar ( apezar | de que está tambem com bons sentimentos) e por que creio naõ devem | tardar as Providencias da Corte, certo porem, que se ellas tardarem, ea | Facçaõ tiver arte, pode tudo attrapalhar, emquanto a Comarca naõ | estiver centralizada devo dar a V. Exa. uma ligeira idea disto ca, e $\mid$ do mizeravel estado da Capital, e suas dependencias, a concluir, pedindo | se esforce a cooperar por a brevidade dos remédios [BNRJ 11]

b. sobre tudo por a es- | colha delles, e sobre as terriveis consequencias, se elles tardarem [BNRJ 11] 
c. deo isto Cauza, aque o dito Intendente, me intregace por Ordem, as Cha $=\mid$ ves dos armazens Reais, para eu por ellas Responder, efazer o Servisso, | etaõ bem aqual o dito Sargento Mor, foce mandado governar, e Commandar | as Villas de Ubatuba e São Sebastiam, para ficarem desvanecidas as ethique $=\mid$ tas Como dito Intendente: immediatamente logo veyo Commandar esta $\operatorname{Pra}=\mid$ ça o Coronel pago Antonio Luiz da Roxa Ferreira [BNRJ 19]

Ao comparar os dados dos sujeitos do século XVIII com os dados do século XIX há diferença na porcentagem de ocorrências de sujeito nulo, contudo nos dois séculos há mais sujeitos nulos do que sujeitos realizados. Depois que apresentarmos os dados do século XX, mostraremos se a predileção do sujeito nulo se manteve em todo o corpus ou apenas nos dois primeiros séculos.

Agora vamos analisar os dados das orações que acompanham a flexão infinitiva no século XIX. Nesse momento, a flexão infinitiva aparece com três tipos de orações: (i) orações encaixadas com preposição; (ii) orações encaixadas com pronomes; (iii) orações encaixadas completivas nominais. Na tabela a seguir, há a distribuição de cada oração de infinitivo flexionado encontradas no corpus do século XIX.

Tabela 4: Tipos de oração com infinitivo flexionado no século XIX

\begin{tabular}{l|l|l|l|l|l|c}
\hline \multicolumn{1}{c|}{ Tipos de Oração } & \multicolumn{2}{c|}{ Sujeito Nulo } & \multicolumn{2}{c|}{$\begin{array}{c}\text { Sujeito } \\
\text { Realizado } \\
\text { \% }\end{array}$} & \multicolumn{2}{c}{ Total } \\
& \multicolumn{2}{c|}{$\mathbf{N}^{\mathbf{0}}$} & \multicolumn{2}{c|}{$\%$} \\
\hline Orações encaixadas com pronomes & 9 & $45 \%$ & 11 & $55 \%$ & 20 & $100 \%$ \\
\hline Orações encaixadas com preposição & 14 & $73,69 \%$ & 5 & $26,31 \%$ & 19 & $100 \%$ \\
\hline Orações encaixadas completivas nominais & 6 & $60 \%$ & 4 & $40 \%$ & 10 & $100 \%$ \\
\hline
\end{tabular}

Os dados apresentados na tabela com os tipos de oração com infinitivo flexionado no século XIX mostram que a maioria das orações são encaixadas com pronomes, 20 orações desse tipo, de um total de 40 , correspondem a $82 \%$ do total de orações de flexão infinitiva. As orações encaixadas com preposição correspondem a 19 ocorrências e $38,78 \%$ das orações do século XIX, enquanto as orações encaixadas completivas nominais apresentam 10 ocorrências, que são $20,40 \%$ do total.

A Tabela 4 indica que o maior número de ocorrências ainda permanece com os sujeitos nulos. Nesse século, a predileção pelo uso do sujeito nulo com a flexão infinitiva permanece.

Há uma diferença ao comparar esses dados com os do século anterior: no século XVIII, a predominância é de orações encaixadas com preposição. O número de ocorrências de oração com preposição é bastante significativo, corresponde a quase $40 \%$ do total, mas no século XIX há uma preferência por infinitivo flexionado em orações com pronome.

Assim, por meio dos dados do século XIX, podemos ver que a preferência pelo sujeito nulo se manteve no português paulista. O sujeito nulo acompanhado da flexão infinitiva aparece mais em orações encaixadas com preposição, são 14 orações encaixadas com preposição e sujeito nulo, mas a maioria das flexões infinitivas está em orações encaixadas com pronome. $\mathrm{Na}$ análise do século $\mathrm{XX}$, poderemos ver se o sujeito nulo é o mais usado nos três séculos ou se há uma mudança no português paulista neste último século. 


\subsection{Os sujeitos no século $\mathrm{XX}$}

O último século a ser analisado no presente trabalho é o século XX, que já apresenta uma diferença: tem o menor número de ocorrências de flexão infinitiva; há apenas 18 flexões infinitivas nas 40 cartas deste século. Os séculos anteriores têm mais do que o dobro de infinitivos flexionados no século XX. Dessa maneira, já é possível dizer que há uma diminuição nas ocorrências de infinitivo flexionado, já que o século XVIII apresenta 55 ocorrências, o século XIX 49 e o século XX apenas 18. Faremos uma comparação com os dados dos séculos anteriores e estabeleceremos se o sujeito nulo também é o que apresenta maior predileção neste século.

Tabela 5: Ocorrências de IF no século XX

\begin{tabular}{l|l|l|l}
\hline Variáveis & Sujeito realizado & Sujeito nulo & Total \\
\hline Quantidade & 12 & 6 & 18 \\
\hline Porcentagem & $66,67 \%$ & $33,33 \%$ & $100 \%$ \\
\hline
\end{tabular}

Ao observar a Tabela 5, acima, podemos ver que o século XX se difere bastante dos séculos anteriores: há mais sujeitos realizados com a flexão infinitiva do que sujeitos nulos. São 66,67\% de sujeitos realizados, que marcam 12 ocorrências, e 33,33\% de sujeitos nulos, que são apenas 6 ocorrências no total de 18. No exemplo em (11), podemos ver algumas ocorrências de flexão infinitiva com sujeito realizado no século XX:

(11) a. Aí come- çamos a pular para chamar a atenção mesmo!!! Ficamos de guarda para ver eles entrarem no ônibus e mais um monte de macaquices que um dia eu te conto melhor e com calma, ok? [FÃ 02]

b. Ah! O cara do correio falou que vai demorar um pouco as fitas desembarcarem por aí porque o correio está com 'excesso de cargas' [FÃ 05]

c. eu tava pensando em mandar uma carta para a gravadora pedindo para eles entregarem uma carta nossa nas mãos do Ian, que tal? [FÃ 12]

Agora, no exemplo em (12) temos orações de infinitivo flexionado com sujeito nulo do século XX:

(12) a. As letras das músicas eu tentei traduzir (as que eu tenho) e ficaram bem “es- tranhas' mesmo, mas que não deixam de serem maravilhosas, não? [FÃ 06]

b. eu preciso declarar ficando a mobilia me pertencendo para depois de minha morte dividirem aos filhos por sorte. [CFWL 08]

c. encarreguem alguem para tomar a direcção dos seus negocios, visto não podermos continuar com tal encargo [CFWL 04]

Quanto às orações em que aparecem as flexões infinitivas no século XX, foram encontradas orações de três tipos: (i) orações encaixadas com preposição; (ii) orações encaixadas com outros conectivos (como pronomes e conjunções); orações encaixadas completivas nominais. 
Tabela 6: Tipos de oração com infinitivo flexionado no século XX

\begin{tabular}{l|l|l|l|l|l|l}
\hline \multicolumn{1}{c|}{ Tipos de Oração } & \multicolumn{2}{|c|}{ Sujeito Nulo } & \multicolumn{2}{c|}{$\begin{array}{c}\text { Sujeito } \\
\text { Realizado }\end{array}$} & \multicolumn{2}{c}{ Total } \\
& \multicolumn{2}{|c|}{$\mathbf{N}^{\mathbf{0}}$} & \multicolumn{2}{c|}{$\mathbf{N}^{\mathbf{0}}$} & \multicolumn{1}{c}{$\mathbf{N}^{\mathbf{0}}$} \\
\hline Orações encaixadas com pronomes & 4 & $33,33 \%$ & 8 & $66,67 \%$ & 12 & $100 \%$ \\
\hline Orações encaixadas com preposição & 1 & $50 \%$ & 1 & $50 \%$ & 2 & $100 \%$ \\
\hline Orações encaixadas completivas nominais & 1 & $25 \%$ & 3 & $75 \%$ & 4 & $100 \%$ \\
\hline
\end{tabular}

A maioria das flexões infinitivas aparece em orações encaixadas com pronomes, são 12 do total de 18 ocorrências. Das orações encaixadas com pronomes, mais de $60 \%$ aparecem com sujeito realizado.

O século XX é o que mais se distancia dos séculos vistos anteriormente. Possui o menor número de ocorrências de flexão infinitiva e o sujeito em destaque com as orações é o sujeito realizado. Provavelmente aparecem mais sujeitos realizados do que sujeitos nulos porque a flexão infinitiva permite identificar qual é o sujeito (MAURER JR., 1968).

\section{Considerações parciais da pesquisa}

A sintaxe diacrônica possibilita compreender o desenvolvimento da língua. A flexão do infinitivo no PB tem sido alvo de uma série de estudos também sob perspectiva diacrônica. No presente estudo, observou-se a flexão do infinitivo nos séculos XVIII, XIX e XX sob uma perspectiva diacrônica. Os dados do português paulista nos mostram que há mais sujeito nulo acompanhando a flexão infinitiva nos séculos XVIII e XIX, o que é reforçado pelo trabalho de Duarte (1995), pois a flexão marca o sujeito, evidenciando os sujeitos nulos. $\mathrm{O}$ sujeito não nulo é crescente no século $\mathrm{XX}$, indicando uma mudança no PB. A presença do sujeito lexical é importante para o surgimento da flexão do infinitivo, e o número elevado de sujeitos não nulos nos dados dos séculos deste estudo reforça essa percepção. A porcentagem de sujeitos não nulos foi crescente nos séculos deste estudo.

Ao compararmos a flexão do infinitivo no PB atual e no PB do século XVIII, percebe-se que a flexão de primeira pessoa do plural não está presente em alguns contextos devido ao desuso do pronome "nós", como mencionado acima, pois houve perda da flexão infinitiva (PIRES, 2006). Isso ocorre porque "a gente" não propõe uma marcação de pessoa, projetando, dessa forma, o enfraquecimento da flexão - como previsto em Galves (1993).

Há ainda questões para discussões futuras sobre a flexão do infinitivo, como os contextos específicos do infinitivo flexionado no corpus destacado e uma separação entre sentenças com sujeito realizado e não realizado. A investigação de tais aspectos é de extrema importância para estudos futuros.

\section{REFERÊNCIAS}

BARBOSA, P.; DUARTE, M. E. L.; KATO, M. A. Null subjects in European and Brazilian Portuguese, Journal of Portuguese Linguistics, v. 4 (2), p. 11-52. 2005.

CANEVER, F. Evidências para um modelo de língua baseado no uso: o infinitivo flexionado no português brasileiro. 2012. 165 f. Dissertação (Mestrado em Linguística) - 
Faculdade de Filosofia, Letras e Ciências Humanas, Universidade de São Paulo, São Paulo, 2012.

CARVALHO, P. H. V. de; MINUSSI, R. D. Do infinitivo impessoal latino ao infinitivo flexionado no português brasileiro: origens e reanálise a flexão de número e pessoa. Estudos linguísticos e literários, Salvador, n. 44, p. 67-100, 2016.

CAVAlCANTE, S. R. de O. O uso de se com infinitivo na História do Português: do Português Clássico ao Português Europeu e Brasileiro Modernos. 2006. 227 f. Tese (Doutorado em Linguística) - Instituto de Estudos da Linguagem, Universidade Estadual de Campinas, Campinas, 2006.

CHOMSKY, N. Lectures on Government and Binding. Dordrecht: Foris, 1981.

Knowledge of language: its nature, origin and use. Westport: Praeger, 1986.

CYRINO, S. M. L. A categoria "INFL" no português brasileiro. Estudos Lingüísticos, v. XXVIII, p. 449-454, 1999.

DUARTE, M. E. L. A perda do princípio "Evite Pronome" no português brasileiro. 1995. 161 f. Tese (Doutorado em Linguística) - Instituto de Estudos da Linguagem, Universidade Estadual de Campinas, Campinas, 1995.

GALVES, C. A Sintaxe do Português brasileiro. Ensaios de Linguística, v. 13, p. 31-50, 1987.

O enfraquecimento da concordância no português brasileiro. In: ROBERTS, I.; KATO, M. (Orgs.). Português brasileiro. Uma viagem diacrônica. Campinas: Editora da UNICAMP, 1993. p. 387-408. UNICAMP, 2001.

GRAVINA, A. P. A natureza do sujeito nulo na diacronia do PB: estudo de um corpus mineiro (1845-1950). 2008. 146 f. Dissertação (Mestrado em Linguística) - Instituto de Estudos da Linguagem, Universidade Estadual de Campinas, Campinas, 2008.

HUANG, C. T. J. On the distribution and reference of the empty categories. Linguistic Inquiry, n. 15, p. 531-74, 1984.

KATO, M. A.; TARALlO, F. Anything you can do in Brazilian Portuguese. In: JAEGGLI, O.; CORVALÁN, C. S (Eds.). Studies in Romance Linguistics. Amsterdam: Foris, 1986. p. 343-358.

KEWITZ, V. Gramaticalização e semanticização das preposições A e PARA no português brasileiro (séc. XIX e XX). 2007. 210 f. Tese (Doutorado em Filologia e Língua Portuguesa) - Faculdade de Filosofia, Letras e Ciências Humanas, Universidade de São Paulo, São Paulo, 2007.

$\mathrm{KROCH}, \mathrm{A}$. Reflexes of grammar in patterns of language change. Language Variation and Change, n. 1, p. 199-244, 1989.

LOPES, C. R. dos S. A inserção de "a gente" no quadro pronominal do português. v. 18. Frankfurt/Madri: Vervuert/Iberoamericana, 2003.

LUZ, G. A. Inflected Infinitive in Romance Languages. Cad. Est. Ling., Campinas, v. 34, p. 7-17, jan./jun. 1994. 
MARINS, J. E. O Parâmetro do Sujeito Nulo: uma análise contrastiva entre o português e o italiano. 2009. 111 f. Dissertação (Mestrado em Letras Vernáculas) - Faculdade de Letras, Universidade Federal do Rio de Janeiro, Rio de Janeiro, 2009.

MARTINS, A. M. Aspects of infinitival construction in the history of Portuguese. 2001 Universidade de Lisboa. Disponível em:

$<$ http://www.clul.ul.pt/files/ana maria martins/MartinsAspectsOfInfinitival.pdf $>$. Acesso em: 5 abr. 2016.

MAURER JR., T. H. O infinitivo flexionado no português: estudo histórico-descritivo. Imprenta. São Paulo: Cia. Ed. Nacional, 1968.

PAIXÃO DE SOUSA, M. C. Língua barroca: sintaxe e história do português nos seiscentos. 2004. 377 f. Tese (Doutorado em Linguística) - Instituto de Estudos da Linguagem, Universidade Estadual de Campinas, Campinas, 2004.

PHPP - Projeto de História do Português Paulista. Descrição do projeto. Disponível em: $<$ http://phpp.fflch.usp.br/>. Acesso em: 13 abr. 2016.

PIRES, A. The minimalist syntax of defective domains: Gerunds and infinitives. Amsterdam: John Benjamins, 2006.

RAPOSO, E. P. The Inflected Infinitive in European Portuguese. Linguistic Inquiry, v. 18, n. 1, p. 85-109, Winter, 1987.

RAPOSO, E. P. Teoria da Gramática: a faculdade da Linguagem. Lisboa: Caminho, 1992.

ROBERTS, I. Verbs and Diachronic Syntax. Dordrecht: Kluwer, 1993.

RODRIGUES, J. M. $O$ Imperfeito do conjuntivo e o infinito pessoal no Português. Boletim da Segunda Classe da Academia das Ciências de Lisboa, Lisboa, n. 8, p. 72-93, 1914

SHEEHAN, M. 'Free' inversion in Romance and the Null Subject Parameter. In: BIBERAUER, T.; HOLMBERG, A.; ROBERTS, I.; SHEEMAN, M. Parametric Variation: Null Subject in Minimalist Theory. Cambridge: Cambridge University Press, 2010. p. 231-262.

TARAllo, F. Relativization Strategies in Brazilian Portuguese. 1983. 273 f. Tese (Doutorado em Linguística) - University of Pennsylvania, Pennsylvania, 1983.

VASCONCELOS, J. L. de. Estudos de Philologia Mirandesa. Lisboa: Imprensa Nacional, 1900.

WERNECKE, H. Zur Syntax des portugiesischen Verbs. Weimar (Programm des Realgymnasiums in Weimar), 1885.

Recebido em: 25/09/2017

Aprovado em: 19/02/2018 